\title{
Selective Binding of Albumin to Gm1 Ganglioside Micelles Containing Paclitaxel
}

\author{
Victoria Leonhard ${ }^{1,2}$, Roxana V. Alasino ${ }^{1,2}$, Ismael D. Bianco ${ }^{1,2,3}$ and Dante M. Beltramo ${ }^{1,2,4 *}$ \\ ${ }^{1}$ Centro de Excelencia en Productos y Procesos de Córdoba (CEPROCOR), Argentina \\ ${ }^{2}$ Consejo Nacional de Investigaciones Científicas y Técnicas (CONICET), Argentina \\ ${ }^{3}$ Departamento de Ciencias Exactas, Físicas y Naturales, Universidad Nacional de La Rioja, Argentina \\ ${ }^{4}$ Laboratorio de Biotecnología, Facultad de Ciencias Químicas, Universidad Católica de Córdoba, Argentina
}

\begin{abstract}
In our previous work we showed that taxanes (paclitaxel (Ptx) and docetaxel(Dtx)) can be spontaneously loaded into monosialoganglioside (GM1) nanomicelles, increasing their water solubility about 6,000 times, to render stable water soluble formulations that could be used as a novel strategy to deliver drugs in cancer. Here, we describe the hydrophobic interaction of Human Serum Albumin (HSA) with GM1 micelles loaded with Ptx, as a strategy that could improve tumour drug accumulation. This interaction is regulated by conditions such $\mathrm{pH}$ and temperature and generates ternary complexes GM1/Ptx/HSA with sizes around 19 to $24 \mathrm{~nm}$ and hydrodynamic radius equivalent to a globular protein of $140-180 \mathrm{kDa}$. These mixed micelles were stable in solution for at least 40 days and also upon freeze-thawing or lyophilization-solubilization cycles. The results of in vitro assays showed that the nano-structures developed are taken up by cell cultures with an antimitotic activity of Ptx on tumoral and nontumoral cell lines that was similar to that observed with the free drug in DMSO solution.
\end{abstract}

Keywords: Gangliosides; Paclitaxel; Albumin; Micelles; Drugdelivery

\section{Introduction}

Several hydrophobic drugs, especially those used in oncological treatments, appear with poor or limited water solubility, rapid phagocytic and renal clearance, and elevated systemic toxicity which represent the major barriers that limit the therapeutic use. Paclitaxel (Ptx) is a potent and one of the most used anticancer agents but is also notorious for its poor water solubility [1]. The drug has been successfully formulated in $50 \%(\mathrm{v} / \mathrm{v})$ polyoxyethylated castor oil $\left(\right.$ Cremophor $\left.\mathrm{EL}^{\circledR}\right)$ and 50\% dehydrated ethanol. However, the large volume of solvent that is required for completely dissolving the drug has been frequently associated with life threatening hypersensitivity reactions [2,3]. At the present, many laboratories have developed strategies to avoid systemic toxicity and to increase the low water solubility of hydrophobic drugs such as Ptx. Liposomes composed of a phospholipid bilayer are capable of encapsulating the active drug [4,5]. Nevertheless liposomes are frequently opsonized by plasma proteins and rapidly removed by the reticuloendothelial system [5]. To overcome this problem, the phopholipids were conjugated to polyethylene glycol to evade the immune system and prolong the duration of exposure [6,7]. However, it has not yet been possible to adapt this strategy for the delivery of Ptx, mainly because under the conditions employed so far, it is rapidly extruded from the bilayer rendering unstable formulations [8]. Other strategy to improve the systemic delivery of water-insoluble drugs is the use of micelles. The major advantages of micelles are: a) selfassembly and $b$ ) smaller size than liposomes (usually within a range of 5-100 nm). The major disadvantage observed for these systems arises mainly from the high instability of the micelles upon dilution [9]. The results reported in our previous work show that micelle forming monosialogangliosides (i.e., GM1 and GM2), with critical micellar concentrations (CMCs) in the order of $10^{-8} \mathrm{M}$, spontaneously interact with Ptx and docetaxel (Dtx) forming water soluble structures that are relatively insensitive to dilution and allow their aqueous delivery and antimitotic activity [10]. One of the major limitations in conventional chemotherapy of cancer is its lack of tumor selectivity; therefore chemotherapeutic agents are distributed nonspecifically in the body where they affect both cancerous and normal cells [11] Numerous drug targeting systems are currently developed or under development [12]. Their use aims to minimize drug degradation and inactivation upon administration, prevent undesirable side effects, and increase drug bioavailability and the fraction of drug delivered in the pathological area. Recently, Paclitaxel was bound to albumin in a noncovalent condition (nab paclitaxel; ABI-007; Abraxane ${ }^{\circledR}$ ) avoiding undesirable effects of the use of co-solvents [13] and also mediating an enhanced anti-tumor effect via a SPARC- albumin interaction [14]. Abraxane ${ }^{\circledR}$ has been approved in at least 40 countries for the treatment of metastatic breast cancer and is under clinical trials for non- smallcell lung cancer. However, the formulation developed has a very limited stability upon reconstitution in saline solution (a maximum of $8 \mathrm{~h}$ refrigerated at $2^{\circ} \mathrm{C}$ to $8^{\circ} \mathrm{C}$ ) and requires the use of a high pressure homogenizer for its production. Therefore, alternative formulations of paclitaxel are still actively sought. We have recently demonstrated that taxanes are spontaneously loaded into monosialoganglioside micelles [10]. Interestingly, we found that upon interaction with blood, GM1/ Ptx micelles interact spontaneously and selectively with albumin (HSA) to give ternary GM1/Ptx/HSA complexes [10]. As albumin binding could improve tumor targeting, in this work we characterized the events involved in the interaction between HSA and GM1/Ptx mixed micelles.

*Corresponding author: D.M. Beltramo, Center of Excellence in Products and Processes Córdoba (CEPROCOR), Ministry of Science and Technology of Córdoba, CEPROCOR Pavilion, CP 5164, St. Mary of Punilla, Cordoba, Argentina, Tel: 54-3541-489651/53 ext.143; Fax: 54-3541-488181; E-mail: dbeltramo@yahoo.com.ar

Received October 12, 2012; Accepted December 27, 2012; Published December 31,2012

Citation: Leonhard V, Alasino RV, Bianco ID, Beltramo DM (2013) Selective Binding of Albumin to Gm1 Ganglioside Micelles Containing Paclitaxel. J Nanomed Nanotechol 4: 159. doi:10.4172/2157-7439.1000159

Copyright: (c) 2013 Leonhard V, et al. This is an open-access article distributed under the terms of the Creative Commons Attribution License, which permits unrestricted use, distribution, and reproduction in any medium, provided the original author and source are credited. 


\section{Materials and Methods}

\section{Materials}

Paclitaxel (Ptx) was from Yunnan Smandbet Co. Ltd. (Kumming, China). Flutax- 1(7-O-[N-(4'-fluoresceincarbonyl)-l-alanyl]taxol) waspurchasedfrom Calbiochem (San Diego, CA). Purified monosialoganglioside GM1 in a sodium salt form was a gift from Dr. P.E.A. Rodriguez. Purified human serum albumin (HSA) 20\% (w/v) with sodium caprylate $(0.04 \mathrm{M})$ and $\mathrm{N}$-acetyltryptophane $(0.04 \mathrm{M})$ as stabilizers was a gift of Laboratorio de Hemoderivados, Universidad Nacional de Córdoba (Córdoba, Argentina). To remove excipients albumin was dialyzed against distilled water or saline and diluted with distilled non pyrogenic water to the final concentration used in each assay. All other chemicals used were of analytical grade.

\section{Methods}

Standard procedure for preparing mixed micelles of GM1, Ptx and HAS Stock solution of GM1 with a concentration of $250 \mathrm{mg} \cdot \mathrm{mL}^{-1}$, was prepared in bidistilled water $24 \mathrm{~h}$ prior to use. The solutions were maintained at $4-8^{\circ} \mathrm{C}$ for $24 \mathrm{~h}$. Then, they were centrifuged at $50,000 \mathrm{~g}$ for $15 \mathrm{~min}$ and the supernatant was filtered through $0.22 \mu \mathrm{m}$. Stock solution of Ptx (50 mg.mL $\left.\mathrm{m}^{-1}\right)$ was prepared in DMSO. The solution of Ptx was slowly added with gentle agitation to the solution of GM1 micelles generating complexes with GM1/Ptx 20/1 molar ratio. The mixtures were incubated at $4^{\circ} \mathrm{C}$ for $24 \mathrm{~h}$ and dialyzed for $24 \mathrm{~h}$ at the same temperature to remove all DMSO. Then these micelles (GM1 or GM1/Ptx) were incubated with pure HSA at different $\mathrm{pH}(3,5$ and $10)$ and temperature $\left(4,37\right.$ and $\left.55^{\circ} \mathrm{C}\right)$ conditions. The interaction was evaluated using incubations of up to 24 hours. All these samples were studied by chromatographic analysis.

\section{Determination of Ptx concentration}

Ptx was determined as described in Leonhard et al. [10]. Briefly, Ptx was extracted from micelles with 10 volumes of ethyl acetate. Then, samples were centrifuged at 2,500 rpm for $5 \mathrm{~min}$, the organic layer was transferred to a clean tube and evaporated to dryness at $40^{\circ} \mathrm{C}$. The dried residue was solubilized in 1 volume of ethanol. Ptx concentration was measured using a Curosil B C18 column $(250 \times 3.20 \mathrm{~mm}$ I.D., particle size $5 \mu \mathrm{m})$ and a Curosil B C18 guard column $(30 \times 4.60 \mathrm{~mm}$ I.D., particle size $5 \mu \mathrm{m}$ ) supplied by Phenomenex. The mobile phase was $60 \%(\mathrm{v} / \mathrm{v})$ acetonitrile and $40 \%(\mathrm{v} / \mathrm{v})$ bidistilled water. Flow rate was 0.7 $\mathrm{mL} \cdot \mathrm{min}^{-1}$ and the eluent was monitored at $227 \mathrm{~nm}$. Chromatography was performed at ambient temperature $\left(20^{\circ} \mathrm{C}\right)$ and the calibration curves of Ptx and Dtx were linear in a range from 5 to $150 \mu \mathrm{g}$.

\section{Determination of ganglioside concentration}

Ganglioside concentrations were measured by the modified colorimetric resorcinol assay [15]. Briefly, $1 \mathrm{~mL}$ of resorcinol reagent and was added to $1 \mathrm{~mL}$ of the samples and heated to $100^{\circ} \mathrm{C}$ for $15 \mathrm{~min}$. (Resorcinol reagent: $2 \mathrm{mg}$ of resorcinol powder dissolved in $0.1 \mathrm{~mL}$ of bidistilled water $+0.8 \mathrm{~mL}$ of $37.9 \%(\mathrm{w} / \mathrm{v}) \mathrm{HCl}+2.5 \mu \mathrm{L}$ of $0.1 \mathrm{M} \mathrm{CuSO}_{4}$ + bidistilled water amount sufficient to reach $1 \mathrm{~mL}$ ). Then, the samples were allowed to cool and the cromophore developed was extracted with $2.5 \mathrm{~mL}$ of $\mathrm{n}$-butyl acetate:n-butanol ( $85 / 15$ by vol). After centrifugation at $2500 \mathrm{rpm}$ for $5 \mathrm{~min}$, the supernatants were removed and measured spectrophotometrically at $580 \mathrm{~nm}$.

\section{Determination of HSA concentration}

The content of protein bound to micelles was determined using a Coomassie Brilliant blue assay or by direct absorbance at $280 \mathrm{~nm}$ [16].

\section{Physical Stability of GM1/Ptx/HSA Mixed Micelles}

\section{Dialysis assay}

Solutions of pure GM1, GM1/Ptx and GM1/Ptx/HSA mixed micelles, with a GM1 concentration of $250 \mathrm{mg} \cdot \mathrm{mL}^{-1}$, underwent extensive dialysis for $72 \mathrm{~h}$ using dialysis membranes with a cut off of 14 $\mathrm{kDa}$ to ensure the outlet of the monomers during the assay. Aliquots of dialisates were taken at $0,24,48$ and $72 \mathrm{~h}$ and total amount of GM1, Ptx and HSA were determined as described above.

\section{Stability of mixed micelles in solution}

GM1/Ptx/HSA mixed micelles were stored for 40 days at $4^{\circ} \mathrm{C}$. Aliquots of samples were taken at various time periods and the amount of soluble Ptx was quantified by HPLC.

\section{Effect of freeze-thawing cycles and lyophilization}

GM1/Ptx/HSA mixed micelles were frozen at $-80^{\circ} \mathrm{C}$ for $24 \mathrm{~h}$. Subsequently the samples were allowed to reach room temperature and then centrifuged at $15,000 \mathrm{~g}$ for $10 \mathrm{~min}$ before measuring the concentrations of HSA, Ptx and GM1 that remained soluble. Lyophilized mixed micelles were dissolved in their initial volume and filtered through a $0.22 \mu \mathrm{m}$ pore before measuring soluble HSA, Ptx and GM1.

\section{Structural characterization of GM1/Ptx/HSA mixed micelles}

Chromatographic analysis Samples and controls were run on an Åkta Explorer 100 system (GE Healthcare) fitted with a Superdex 200 column, previously equilibrated with $50 \mathrm{mM}$ phosphate buffer ( $\mathrm{pH} 7.0$ ) and $150 \mathrm{mM} \mathrm{NaCl}$ at a rate of $0.4 \mathrm{~mL} \cdot \mathrm{min}^{-1}$. The elution profile was followed using a UV-detector at 227 and $280 \mathrm{~nm}$. Ganglioside levels were quantified as described above.

\section{Electron Microscopy}

The morphology of micelles was detected using a JEOL JEM-1200 EX II transmission electron microscope at a magnification of $250 \mathrm{~K}$. Samples were prepared by loading $50 \mu \mathrm{L}$ in a carbon grid, allowed to stand for $5 \mathrm{~min}$ and then dried. Then the sample excess was washed out with distilled water. Carbon grids were then incubated with $50 \mu \mathrm{L}$ of $10 \%$ uranil acetate solution for $1 \mathrm{~min}$ and then dried.

\section{Chemical stability of Ptx in GM1/Ptx/HSA mixed micelles}

To evaluate the ability of the structure to protect $\mathrm{Ptx}$ against alkaline hydrolysis GM1/Ptx/HSA mixed micelles were incubated at $\mathrm{pH} 10$ at room temperature $\left(25+1^{\circ} \mathrm{C}\right)$. Aliquots of samples were taken at various time periods and the amount of soluble Ptx was quantified by HPLC. A solution of Ptx in ethanol 50\% was used as a control.

\section{In vitro cytotoxicity of GM1/Ptx/HSA mixed micelles on tumoral and non-tumoral cell lines}

HeLa (Human epithelial carcinoma of cervix), Hep2 (Human epithelial carcinoma of larynx), Vero (African green monkey epithelial kidney) and MA (monkey epithelial kidney) cell lines were cultured in MEM medium supplemented with $10 \%$ of fetal bovine serum (NATOCOR, Córdoba, Argentina) at $37^{\circ} \mathrm{C}$ with $5 \% \mathrm{CO}_{2}$. Cell monolayers at $90 \%$ confluence were incubated during $24 \mathrm{~h}$ with increasing concentration of GM1, Ptx, GM1/Ptx $(20 / 1 \mathrm{~mol} / \mathrm{mol})$ and GM1/Ptx/HSA micelles. The amounts of surviving cells after incubation were evaluated by a MTT staining assay. The IC50 values, or the concentrations of various preparations at which the cell growth 
inhibition was $50 \mathrm{M} \%$ compared to untreated control cells, were estimated (or extrapolated) from the dose-response curves.

\section{Results}

\section{Characterization of the interaction of GM1/Ptx micelles with HAS}

Several attempts have been performed in recent years to formulate taxanes associated to albumin [17-19]. The rationale behind this approach was that many tumours over express gp60 receptors which are specific for albumin, and once activated, could allow for transport of albumin complexes across blood vessel wall barriers into underlying tumour tissue [20]. In this context, we have recently shown that GM1 micelles spontaneously load taxanes forming mixed micelles that incorporate HSA upon incubation with human plasma [10]. Based on the above mentioned results it was of interest to characterize the interaction of GM1/Ptx micelles with HSA. First, we evaluated the temperature dependence of the association of HSA with GM1/Ptx micelles using a size exclusion column. The incubation at $37^{\circ} \mathrm{C}$ showed the presence of three peaks. We also note that the peak that correlates with a hydrodynamic radius of a globular protein of $\sim 185 \mathrm{kDa}$ increased as a function of incubation time proportionally to the reduction of the peak corresponding to free HSA (Figure 1).

Whereas almost no association was observed when the incubation was performed at $4^{\circ} \mathrm{C}$ during $24 \mathrm{~h}$ (data not shown), we observed a fast reduction of the peak corresponding to free HSA with the appearance of a new eluting peak with a hydrodynamic radius equivalent to that of a globular protein of $\sim 140 \mathrm{kDa}$ upon incubation of HSA with GM1/Ptx micelles at $55^{\circ} \mathrm{C}$ (Figure 2). Interestingly, chromatographic patterns of $\mathrm{GM} 1 / \mathrm{Ptx}$ micelles prepared at $55^{\circ} \mathrm{C}$ showed that the $\sim 280 \mathrm{kDa}$ micellar peak of GM1/Ptx that normally appears at low temperature $\left(4-8^{\circ} \mathrm{C}\right)$, completely disappeared (Figure 3 ). These results suggest that heating induces a marked destabilization of the micelles, even in presence of Ptx, condition that was shown to stabilize mixed micelles formed at room temperature [10]. However, when GM1/Ptx micelles were heated at $55^{\circ} \mathrm{C}$ and then incubated with HSA, the incorporation of HSA led to the formation of ternary micelles (GM1/Ptx/HSA) that did not dissociate upon size-exclusion chromatography indicating a shift in the equilibrium favoring the micellar state (Figure 3).

Further studies showed that the presence of $\mathrm{NaCl}$ up to $0.5 \mathrm{M}$ did not prevent the interaction of HSA with GM1/Ptx micelles, suggesting that the association is not dependent on electrostatic interactions but is rather hydrophobically driven (data not shown). This result is in agreement with previous results that demonstrate that GM1 micelles bind albumin by hydrophobic interaction [21,22]. It is well known that HSA undergoes a reversible denaturation that exposes part of its hydrophobic residues upon incubation at acid $(\mathrm{pH} \leq 4.3)$ or alkaline $(\mathrm{pH} \geq 10)$ media $[23,24]$. In agreement with this, upon incubation of HSA with GM1 micelles at $\mathrm{pH} 3$ we observed that about $85 \%$ of HSA is associated to the micelles, (Figure 4), while at pH 7 only around $35 \%$ of HSA interacted with them (Figure 1). When GM1 micelles were preincubated with HSA at different $\mathrm{pHs}(3,5$ and 7$)$ before the incubation with Ptx we observed that the amount of Ptx that could be incorporated into the micelles was significantly reduced, mainly at acid pHs (Table $1)$.

These results show that the best condition for the simultaneous incorporation of Ptx and HSA in GM1 micelles was observed when GM1 micelles were first loaded with Ptx and then with HSA at $\mathrm{pH}$ 3 (Figure 4). Therefore, in order to assess the saturation level of the

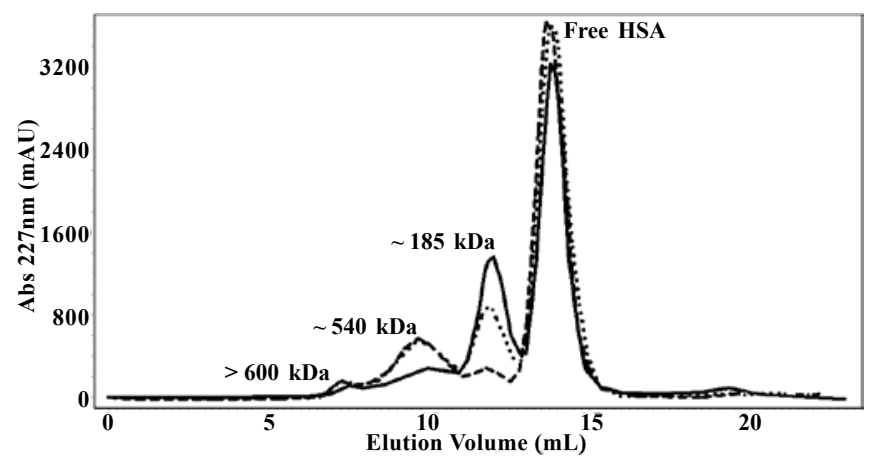

Figure 1: Size-exclusion chromatographic patterns of GM1/Ptx 20/1 molar ratio micelles incubated with $\mathrm{HSA}(\mathrm{HSA} / \mathrm{GM} 11: 1 \mathrm{w} / \mathrm{w})$ at $\mathrm{pH} 7$ and $37^{\circ} \mathrm{C}$ for: 1 h ( --------), $4 \mathrm{~h}$ ( ........) and $24 \mathrm{~h}$ (—).

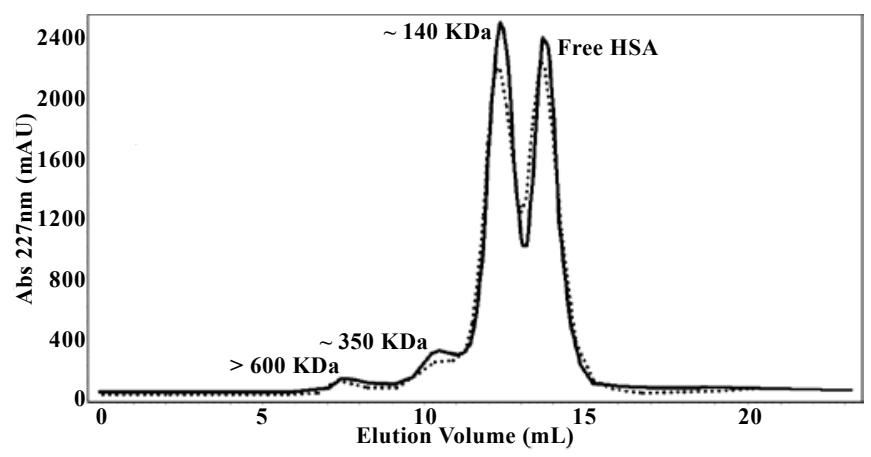

Figure 2: Size-exclusion chromatographic patterns of GM1/Ptx 20/1 molar ratio micelles incubated with $\mathrm{HSA}(\mathrm{HSA} / \mathrm{GM} 11: 1 \mathrm{w} / \mathrm{w})$ at $\mathrm{pH} 7$ and $55^{\circ} \mathrm{C}$ for: 1 $(\ldots \ldots . .$.$) and 4 \mathrm{~h}(-)$.

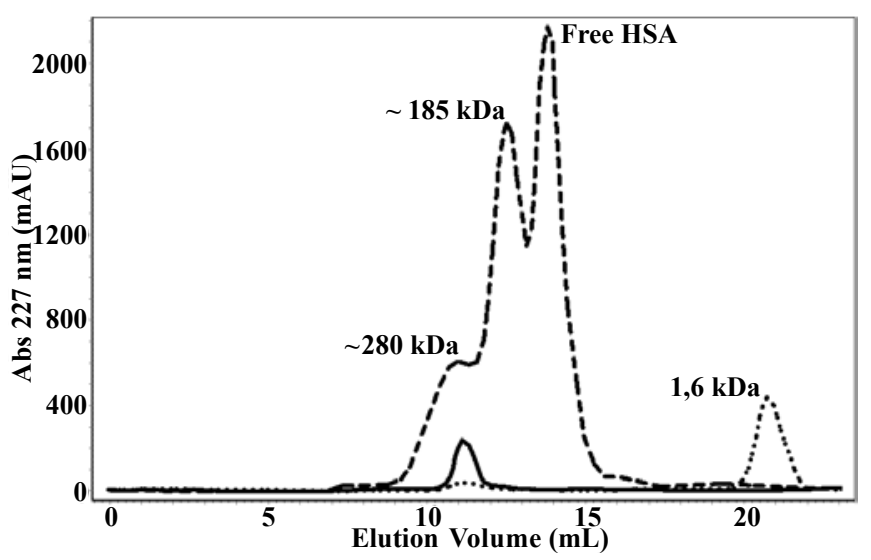

Figure 3: Size-exclusion chromatographic patterns of GM1/Ptx 20/1 molar ratio micelles at: $4^{\circ} \mathrm{C}(-) ; 55^{\circ} \mathrm{C}(\ldots \ldots \ldots)$ and $\mathrm{GM} 1 / \mathrm{Ptx} 20 / 1$ micelles at $55^{\circ} \mathrm{C}$ incubated with HSA (HSA/GM1 1:1 w/w) at $55^{\circ} \mathrm{C}$ for $1 \mathrm{~h}(------)$.

micelles we incubated GM1/Ptx micelles with increasing amounts of HSA (Figure 5). These studies revealed that GM1/Ptx micelles reached saturation at 1:1 w/w HSA:GM1 ratio (Figure 5 and data not shown).

One of the major problems with micellar systems as drug delivery vehicles is the unstability upon dilution that has been mainly associated to high CMCs and fast equilibrium between monomers and micelles $[9,25,26]$. Although gangliosides have lower CMCs than 


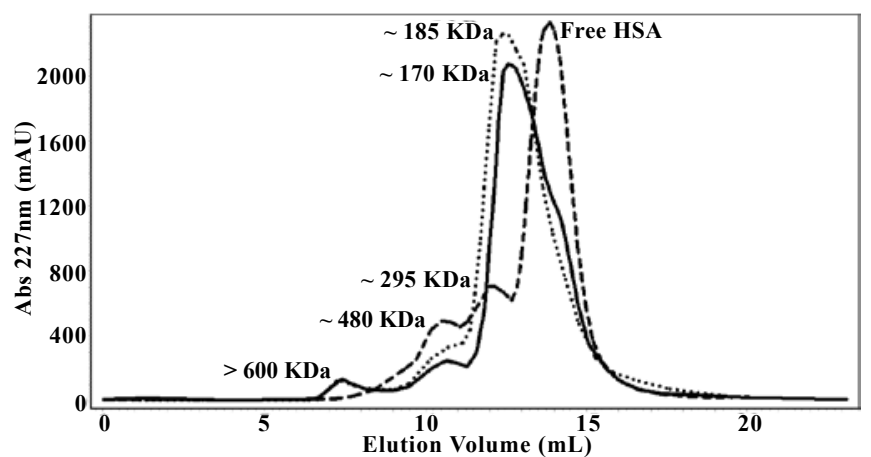

Figure 4: Size-exclusion chromatographic patterns of GM1/Ptx 20/1 molar ratio micelles incubated with HSA (HSA/GM1 1:1 w/w) at: pH 7 (------); 5 (-) and $3(. . . . .$.$) for 24 \mathrm{~h}$. Then samples of $\mathrm{pH} 3$ and 5 were returned to $\mathrm{pH} 7$ after $24 \mathrm{~h}$. Incubation temperature was $37^{\circ} \mathrm{C}$ for all samples.

\begin{tabular}{lll}
\hline & Soluble Ptx (\%) & \\
\cline { 2 - 3 } $\mathbf{p H}$ & GM1/Ptx & GM1/HSA/Ptx \\
\hline 3 & 96 & 54 \\
5 & 94 & 20 \\
7 & 94 & 76 \\
\hline
\end{tabular}

Note: A solution of Ptx (50 mg.mL-1) in DMSO was slowly added with gentle agitation to solutions of $\mathrm{GM} 1$ and $\mathrm{GM} 1 / \mathrm{HSA}(1: 1 \mathrm{w} / \mathrm{w}$ ratio) prepared at different pH conditions: 3, 5 and 7 generating complexes with GM1/Ptx 20/1 molar ratio. The mixtures were incubated at $4^{\circ} \mathrm{C}$ for $24 \mathrm{~h}$ and dialyzed for $24 \mathrm{~h}$ at the same temperature to remove all DMSO. Then, Ptx was measured as described in Materials and Methods

Table 1: Interaction of Ptx with GM1 micelles and GM1 micelles pre-incubated with $\mathrm{HSA}$ at different $\mathrm{pHs}(3,5$ and 7$)$

most amphiphiles, the high turnover of their monomer constituents could still lead to stability problems upon dilution [27]. We have recently demonstrated that loading of Ptx into GM1 micelles produced a dynamical stabilization of the structure. Whereas the reduction of GM1 after the dialysis of pure micelles was $24 \%$, an extensive dialysis of GM1/Ptx complexes showed only a 5\% reduction of GM1 [10]. When albumin binds to GM1/Ptx micelles, the reduction in the amount of GM1 was $6+1 \%$ after $24 \mathrm{~h}$ dialysis, indicating that these new mixed complexes are also very stable. Although the results of the dialysis experiments suggested a high aqueous stability of the micelles, we also determined the long-term stability in solution of the GM1/Ptx/HSA mixed micelles. It was observed that the amount of Ptx that remained soluble was not affected when stored for at least 40 days at $4^{\circ} \mathrm{C}$ (data not shown). Moreover, at least $95 \%$ of GM1/Ptx/HSA mixed micelles were resolubilized after freeze-thawing cycles or after lyophilisation (data not shown).

\section{Chemical stability of Ptx in GM1/Ptx/HSA mixed micelles}

Previous studies suggested that Ptx is located in the hydrophobic core of the GM1 micelles [10]. We also observed that incorporated Ptx has no contact with the surrounding medium, being protected against hydrolysis of its ester bond when the micelles were incubated in alkaline $\mathrm{pH}$. In this context, we evaluated whether albumin binding to the micelle could affect its ability to protect Ptx against alkaline hydrolysis. Figure 6 shows that while almost no degradation was observed when Ptx was associated with GM1 micelles, more than $90 \%$ of free Ptx was hydrolyzed in $5 \mathrm{~h}$ at $\mathrm{pH} 10$ [10]. For GM1/Ptx/HSA mixed micelles it was observed that approximately $50 \%$ of the drug was hydrolyzed in the same period of time (Figure 6). This result suggests that the new structures formed when albumin is bound to the micelles are more loosely packed.

The fact that water solutions of GM1/Ptx/HSA mixed micelles were optically clear (O.D. at $600 \mathrm{~nm}<0.100)$ impaired the use of dynamic light scattering to characterize their average size. Therefore, transmission electron microscopy (TEM) was used in order to evaluate the form and size distribution of these mixed micelles (Figure 7). Our previous studies showed that GM1 micelles have two populations of different sizes, one with an average diameter of 9-10 nm and other of $27-28 \mathrm{~nm}$. We also demonstrated that the incorporation of Ptx produce a shift toward a single micelle population of $9-12 \mathrm{~nm}$ [10]. Figure 7 shows that GM1/Ptx/HSA mixed micelles present one population of micelles with an average diameter of 19-24 nm.

In our previous investigation, we showed that GM1/Ptx micelles produce similar cytotoxic effects to those of free Ptx in DMSO [10] In this study, their interest was to assess whether the interaction of the micelle with the HSA molecule produces an alteration in the cellular uptake of the drug and its subsequent in-vitro effect.

To evaluate the cellular uptake we used a fluorescently labelled derivative of Ptx (Flu-Tax). As shown in figure 8, the kinetic profile of Ptx delivery from GM1/Ptx/HSA mixed micelles to a fibroblast cell line was similar to that from GM1/Ptx micelles and from a control solution in DMSO.

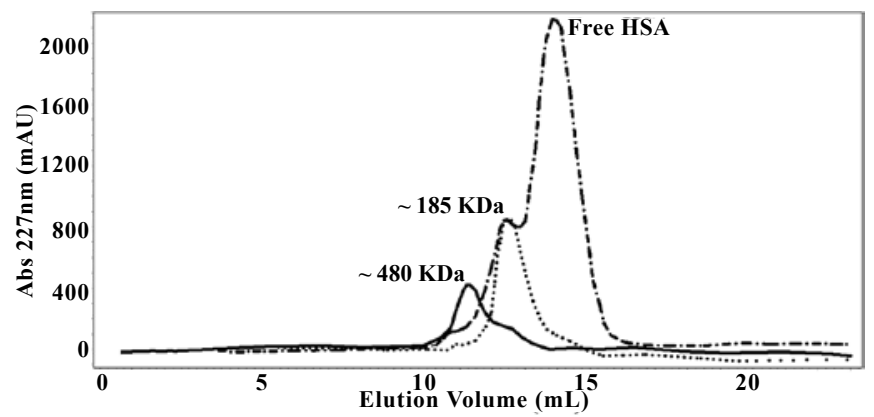

Figure 5: Size-exclusion chromatographic patterns of GM1/Ptx 20/1 molar ratio micelles incubated with increasing amounts of $\mathrm{HSA}$ at $\mathrm{pH} 3$ and $37{ }^{\circ} \mathrm{C}$ for $24 \mathrm{~h}$ to reach different HSA/GM1 w/w ratio: $1 / 2(\quad), 1 / 1(\ldots \ldots \ldots)$ and $4 / 1$ (_-_-_-_-_- )

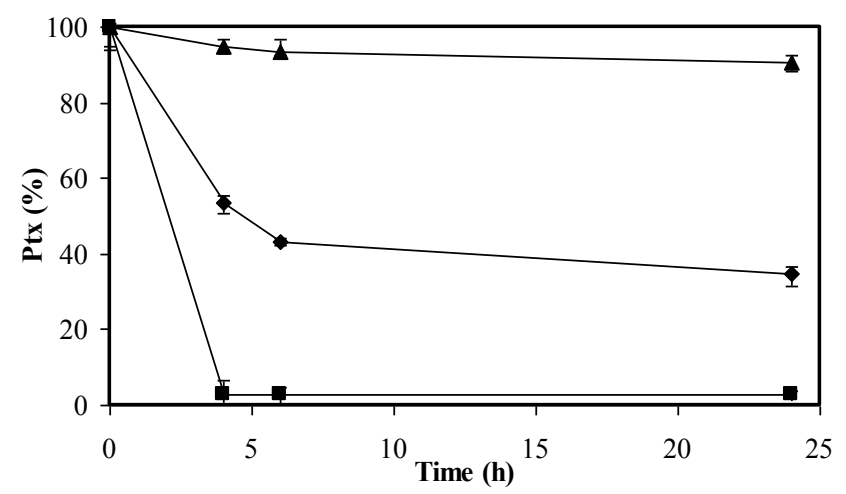

Figure 6: Effect of $\mathrm{pH} 10$ on Ptx stability. GM1/Ptx 20/1 molar ratio micelles $(\rightarrow-$, GM1/Ptx/HSA mixed micelles $\bullet$ ) and Ptx $(50 \%$ EtOH $)(\rightarrow-$. Error bars indicate the SD of the mean $(n=3)$. 
Citation: Leonhard V, Alasino RV, Bianco ID, Beltramo DM (2013) Selective Binding of Albumin to Gm1 Ganglioside Micelles Containing Paclitaxel. J Nanomed Nanotechol 4: 159. doi:10.4172/2157-7439.1000159

Moreover cytotoxic activity of paclitaxel incorporated into GM1/ Ptx and GM1/Ptx/HSA micelles was assessed against tumoral (Hep-2 and HeLa) and non-tumoral (Vero and MA) cells and compared with Ptx in DMSO as control. Figure 9 shows the cytotoxic effect of Ptx on Vero (Figure 9A) and Hep-2 cells (Figure 9B). These results show not significant differences between the IC50 values of any of the micelles (GM1/Ptx, GM1/Ptx/HSA) in relation to the control. The results obtained for MA and HeLa cells were similar to those obtained for Vero and Hep-2 respectively (data not shown). On the other hand, GM1 displayed almost no cytotoxic activity (Figure 9). These results clearly
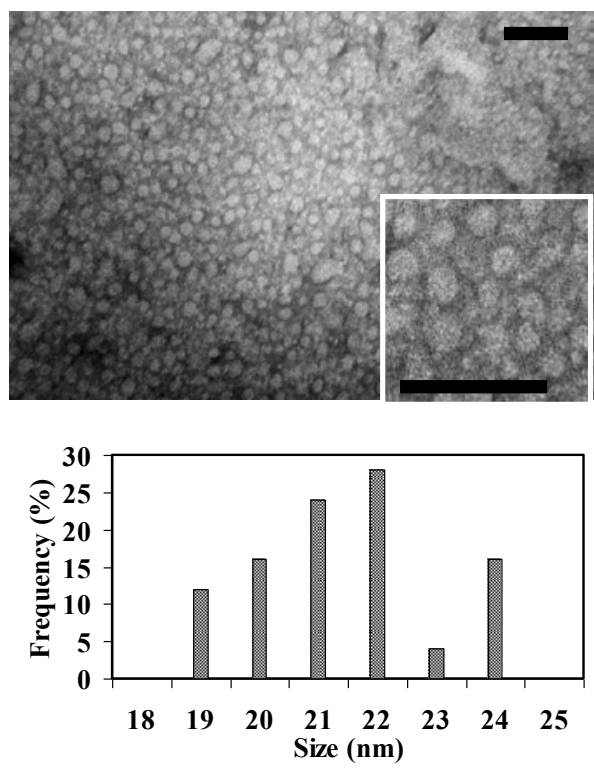

Figure 7: Electronmicrography and frequency histogram of GM1/Ptx/HSA mixed micelles. Size bar: $100 \mathrm{~nm}$.

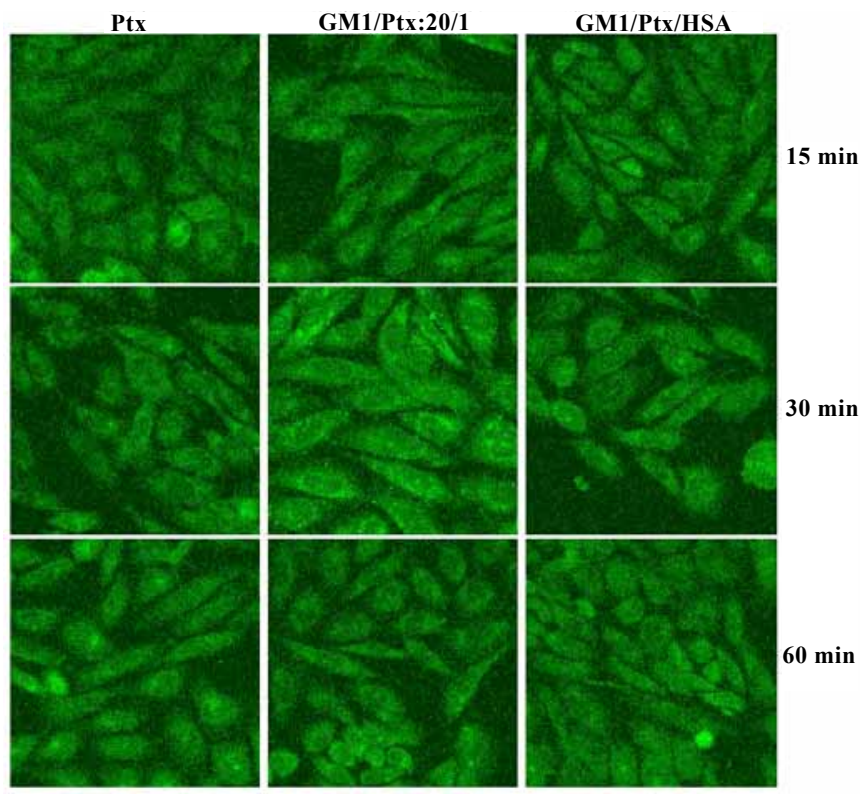

Figure 8: Cellular uptake of Ptx from a solution in DMSO and from GM1/Ptx $20 / 1$ molar ratio micelles and GM1/Ptx/HSA mixed micelles at 15, 30 and 60 $\min$.
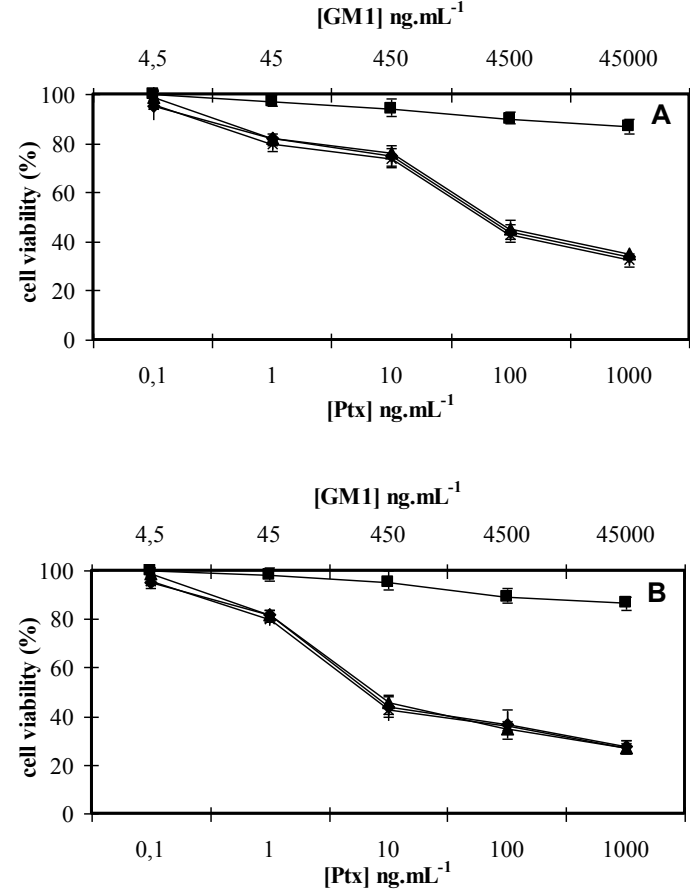

Figure 9: In-vitro cytotoxic effects GM1 ( $\rightarrow$ ), Ptx $(\longrightarrow)$, GM1/Ptx 20/1 molar ratio micelles $(\rightarrow-)$ and GM1/Ptx/HSA mixed micelles $(-)$ on: $(\mathrm{A})$ Vero and (B) Hep-2 cells. Error bars indicate the SD of the mean $(n=3)$.

indicate that Ptx can be released from ganglioside micelles into the cells where it binds to the cytoskeleton blocking the mytotic activity.

\section{Discussion}

Gangliosides are sialic acid-containing glycosphingolipids constituents of the plasma membrane that are mostly restricted to the outer leaflet of the bilayer [28-31]. Because of this orientation, gangliosides have been implicated in a variety of cell surface events such as recognition phenomena and biotransduction of membranemediated information [32-36]. Gangliosides are complex lipids with a strong amphiphilic character due to the big saccharidic headgroup and the double tailed hydrophobic moiety. In aqueous solutions most of them self-assemble spontaneously as micelles with a very low CMC $\left(\sim 10^{-10}-10^{-8} \mathrm{M}\right)$ and aggregation number in the order of hundreds $[27,37]$.

Previous results show that ganglioside micelles are able to spontaneously load hydrophobic oncological drugs like taxanes in aqueous solution without any complex process. Specifically, GM1 micelles increased the water solubility of Ptx up to 6,000 fold, from around $1 \mu \mathrm{g} \cdot \mathrm{mL}^{-1}$ to $6 \mathrm{mg} \cdot \mathrm{mL}^{-1}$. This is in agreement to the concentrations present in the commercially approved formulations of Ptx $\left(\right.$ Taxol $^{\circledR}$ and Abraxane ${ }^{\circledR}$ ). Standard formulations of taxanes require use of solvents such as Cremophor ${ }^{\circledR}$ or Tween, which contribute to some toxicities associated to the paclitaxel-based therapy. To overcome these drawbacks, nanoparticle HSA-bound paclitaxel has been recently approved and is available commercially as Abraxane ${ }^{\circledR}$. However, this formulation is prepared by high pressure homogenization of albumin and paclitaxel, leading to the formation of a colloidal suspension with very limited stability. Research on drug delivery systems has greatly advanced; however, the ability to achieve high targeting efficiency at 
the tumor site and associated cells remains as a significant challenge for the development of micelle-mediated drug delivery systems. In this context, it has been shown that albumin binding to the gp60 receptor of endothelial cells could promote transcytosis to the interstitial space near the tumor, where its interaction with the tumor secreted protein SPARC (secreted protein, acidic and rich in cysteine) may result in intratumoral accumulation of albumin bound paclitaxel $[14,20]$. Previous results showed that upon interaction with human blood, GM1/Ptx mixed micelles are able to interact spontaneously and selectively with HSA to give a tertiary GM1/Ptx/HSA complex [10]. So, the aim of this work was to study the interaction of these loaded micelles to human serum albumin (HSA), a carrier molecule that could improve tumor drug accumulation. It was observed that the association of HSA with GM1/Ptx micelles was not modified by the presence of high saline concentrations suggesting that the interaction is of hydrophobic nature. However, it was highly dependent of conditions such temperature and $\mathrm{pH}$. The interaction of HSA with GM1/Ptx mixed micelles becomes more favorable as the temperature increases, being higher when reaching $55^{\circ} \mathrm{C}$. On another hand, the peak corresponding to GM1/Ptx micelles when the drug is loaded at $4^{\circ} \mathrm{C}$ completely disappeared when GM1/Ptx micelles were previously heated at $55^{\circ} \mathrm{C}$. This result suggests that heating induces changes in the structure that strongly affect their monomer-micellar equilibrium, even in presence of Ptx. Nevertheless, when heated mixed micelles were incubated with HSA we observed the peak corresponding to GM1/Ptx/HSA and the disappearance of the peak corresponding to GM1 monomers. This suggests that the incorporation of HSA would play a stabilizing function on the micellar structure. When evaluating the $\mathrm{pH}$ effects on the interaction of GM1/Ptx complexes with HSA, we observed that at $\mathrm{pH} 3$, where HSA is reversibly denatured and exposes part of its hydrophobic residues, we obtained micelles with a hydrodynamic volume equivalent to a $185 \mathrm{kDa}$ globular protein and observed that about $85 \%$ of HSA ended associated with the micelles. When GM1 micelles were associated with HSA prior to Ptx loading, we observed that Ptx incorporation was partially impaired. This result was more evident on acid $\mathrm{pH}$ where the micelle was associated with a higher amount of HSA. Besides that the binding to HSA somewhat increased the size of the GM1/Ptx micelles (Figure 6), it is important to note that this interaction results in a decrease of about $50 \%$ in the protection against alkaline hydrolysis that gave the GM1 micelle to Ptx. This means that some structural change occurs in the complex upon albumin binding that leaves the drug more exposed to external aqueous environment. The binding of albumin to the GM1/Ptx micelle does not alter the uptake of the drug in cell cultures. In this connection in vitro studies showed that GM1/Ptx/HSA micelles interact and release their content to non-tumoral (Vero and MA) and tumoral (Hep-2 and $\mathrm{HeLa}$ ) cells. IC50 values obtained next to $24 \mathrm{~h}$ of incubation were of 90 and 95 ng.mL $\mathrm{mL}^{-1}$ for Vero and MA cells and 8.0 and 9 ng.mL ${ }^{-1}$ for Hep- 2 and HeLa cells. It is also important to remark that these IC50s are similar to those obtained with other delivery systems of taxanes $[38,39]$. In addition, fluorescence assays showed that Ptx incorporation into the cells begins almost immediately next to the exposure (15 min). As expected, the intensity of this fluorescence was quite low because in short incubation times the proportion of the incorporated drug is very little. These trials were designed in this way to evaluate differences in the kinetics of incorporation of free Ptx formulated in respect of micelles and micelles with albumin, since at times over 12 hours the cytotoxic effects of the drug begin to be observed [38-40].

\section{Conclusion}

These results disclose a novel HSA covered self-assembled nanomicellar system for the aqueous delivery of Ptx [41]. In summary, the results described here in show that:

Aqueous solutions of GM1/Ptx micelles with a Ptx concentration of $6 \mathrm{mg} \cdot \mathrm{mL}^{-1}$ are able to spontaneously interact with HSA without the use of high-pressure homogenization [10].

The interaction of HSA with GM1/Ptx micelles is mainly hydrophobic as the presence of $\mathrm{NaCl}$ up to $0.5 \mathrm{M}$ did not prevent the interaction.

The higher sensitivity of Ptx to the alkaline hydrolysis suggests a more loose packing of the GM1/Ptx/HSA micelles in relation to GM1/Ptx micelles.

- The GM1/Ptx/HSA micelles are stable in aqueous solution for at least 40 days when kept refrigerated.

The GM1/Ptx/HSA structures are stable upon dilution, freezethawing cycle and lyophilization.

The binding of HSA to the GM1/Ptx micelles does not impair the uptake and biological effect of the Ptx in cell cultures, with the potential of increase the accumulation in the tumor via SPARC interaction. Altogether, the physico-chemical properties and the good biocompatibility of the system open the possibility to use this platform for the design of novel nanocarriers for hydrophobic or amphipathic active pharmaceutical ingredients.

Further studies are in progress to evaluate the in vivo activity of this delivery system and its potential to incorporate other active pharmaceutical ingredients.

\section{Acknolwledgement}

This work was supported by grants from CONICET to Drs. Beltramo and Bianco, PIP 11220100100502 and PIP 11220090100732 from CONICET. The authors declare no conflict of interest. RVA, IDB and DMB are research staff and $\mathrm{VL}$ is a fellow of CONICET (Consejo Nacional de Investigaciones Científicas y Tecnológicas). We wish to thank Dr. P.E.A. Rodríguez for supplying us the samples of purified GM1 and C. Nome for electron microscopy images.

\section{References}

1. Safavy A, Raisch KP, Khazaeli MB, Buchsbaum DJ, Bonner JA (1999) Paclitaxel derivatives for targeted therapy of cancer: toward the development of smart taxanes. J Med Chem 42: 4919-4924.

2. Weiss RB, Donehower RC, Wiernik PH, Ohnuma T, Gralla RJ, et al. (1990) Hypersensitivity reactions from taxol. J Clin Oncol 8: 1263-1268.

3. Kloover JS, den Bakker MA, Gelderblom H, van Meerbeeck JP (2004) Fatal outcome of a hypersensitivity reaction to paclitaxel: a critical review of premedication regimens. $\mathrm{Br} \mathrm{J}$ Cancer 90: 304-305

4. Kunstfeld R, Wickenhauser G, Michaelis U, Teifel M, Umek W, et al. (2003) Paclitaxel encapsulated in cationic liposomes diminishes tumor angiogenesis and melanoma growth in a "humanized" SCID mouse model. J Invest Dermato 120: $476-482$.

5. Torchilin VP (2005) Recent advances with liposomes as pharmaceutical carriers. Nat Rev Drug Discov 4: 145-160.

6. O'Shaughnessy JA (2003) Pegylated liposomal doxorubicin in the treatment of breast cancer. Clin Breast Cancer 4: 318-328.

7. Photos PJ, Bacakova L, Discher B, Bates FS, Discher DE (2003) Polymer vesicles in vivo: correlations with PEG molecular weight. J Control Release 90: 323-334

8. Straubinger RM, Balasubramanian SV (2005) Preparation and characterization of taxane-containing liposomes. Methods Enzymol 391: 97-117.

9. Torchilin VP (2007) Micellar nanocarriers: pharmaceutical perspectives. Pharm Res 24: 1-16. 
Citation: Leonhard V, Alasino RV, Bianco ID, Beltramo DM (2013) Selective Binding of Albumin to Gm1 Ganglioside Micelles Containing Paclitaxel. J Nanomed Nanotechol 4: 159. doi:10.4172/2157-7439.1000159

10. Leonhard V, Alasino RV, Bianco ID, Garro AG, Heredia V, et al. (2012) Selfassembled micelles of monosialogangliosides as nanodelivery vehicles for taxanes. J Control Release 162: 619-627.

11. Ross JS, Schenkein DP, Pietrusko R, Rolfe M, Linette GP, et al. (2004) Targeted therapies for cancer 2004. Am J Clin Pathol 122: 598-609.

12. Musacchio T, Torchilin VP (2011) Recent developments in lipid-based pharmaceutical nanocarriers. Front Biosci 16: 1388-1412

13. Ibrahim NK, Desai N, Legha S, Soon-Shiong P, Theriault RL, et al. (2002) Phase I and pharmacokinetic study of ABI-007, a Cremophor-free, protein-stabilized, nanoparticle formulation of paclitaxel. Clin Cancer Res 8: 1038-1044.

14. Fukunaga-Kalabis M, Herlyn M (2007) Unraveling mysteries of the multifunctional protein SPARC. J Invest Dermatol 127: 2497-2498.

15. Miettinen T, Takki-Luukkainen IT (1959) Use of butyl acetate in determination of sialic acid. Acta Chem Scand 13: 856-858.

16. Garro AG, Beltramo DM, Alasino RV, Leonhard V, Heredia V, et al. (2011) Reversible exposure of hydrophobic residues on albumin as a novel strategy for formulation of nanodelivery vehicles for taxanes. Int J Nanomedicine 6 : 1193-1200.

17. Desai NP, Tao C, Yang A, Louie L, Yao Z, et al. (2004) American BioScience Inc., assignee, Protein stabilized pharmacologically active agents, methods for the preparation there of and methods for the us thereof, United States Patent 6749868 June 1517, USA.

18. Paal K, Shkarupin A, Beckford L (2007) Paclitaxel binding to human serum albumin--automated docking studies. Bioorg Med Chem 15: 1323-1329.

19. Bertucci C, Cimitan S, Riva A, Morazzoni P (2006) Binding studies of taxanes to human serum albumin by bioaffinity chromatography and circular dichroism. J Pharm Biomed Analysis 42: 81-87.

20. Gradishar WJ (2006) Albumin-bound paclitaxel: a next-generation taxane Expert Opin Pharmacother 7: 1041-1053.

21. Tomasi M, Roda LG, Ausiello C, D'Agnolo G, Venerando B, et al. (1980) Interaction of GMI ganglioside with bovine serum albumin: formation and isolation of multiple complexes. Eur J Biochem 111: 315-324.

22. Venerando B, Roberti S, Sonnino S, Fiorilli A, Tettamanti G (1982) Interactions of ganglioside GM1 with human and fetal calf sera. Formation of gangliosideserum albumin complexes. Biochim Biophys Acta 692: 18-26.

23. El Kadi N, Taulier N, Le Huérou JY, Gindre M, Urbach W, et al. (2006) Unfolding and refolding of bovine serum albumin at acid $\mathrm{pH}$ : ultrasound and structural studies. Biophys J 91: 3397-3404.

24. Dockal M, Carter DC, Rüker F (2000) Conformational transitions of the three recombinant domains of human serum albumin depending on $\mathrm{pH}$. J Biol Chem 275: 3042-3050

25. Gaucher G, Dufresne MH, Sant VP, Kang N, Maysinger D, et al. (2005) Block copolymer micelles: preparation, characterization and application in drug delivery. J Control Release 109: 169-188.
26. Lukyanov AN, Torchilin VP (2004) Micelles from lipid derivatives of watersoluble polymers as delivery systems for poorly soluble drugs. Adv Drug Deliv Rev 56: $1273-1289$.

27. Formisano S, Johnson ML, Lee G, Aloj SM, Edelhoch H (1979) Critical micelle concentrations of gangliosides. Biochemistry 18: 1119-1124.

28. Fishman PH, Brady RO (1976) Biosynthesis and function of gangliosides Science 194: 906-915.

29. Hakomori S (1981) Glycosphingolipids in cellular interaction, differentiation, and oncogenesis. Annu Rev Biochem 50: 733-764.

30. Wiegandt $H$ (1982) The gangliosides. Adv Neurochem 4: 149-223.

31. Fishman PH (1982) Role of membrane gangliosides in the binding and action of bacterial toxins. J Membr Biol 69: 85-97.

32. Moss J, Fishman PH, Manganiello VC, Vaughan M, Brady RO (1976) Functional incorporation of ganglioside into intact cells: induction of choleragen responsiveness. Proc Natl Acad Sci USA 73: 1034-1037.

33. Spiegel S, Ravid A, Wilchek M (1979) Involvement of gangliosides in lymphocyte stimulation. Proc Natl Acad Sci U S A 76: 5277-5281.

34. Spiegel S, Wilchek M (1981) Membrane sialoglycolipids emerging as possible signal transducers for lymphocyte stimulation. J Immunol 127: 572-575.

35. Markwell MA, Svennerholm L, Paulson JC (1981) Specific gangliosides function as host cell receptors for Sendai virus. Proc Natl Acad Sci U S A 78 : 5406-5410.

36. Yamada KM, Critchley DR, Fishman PH, Moss J (1983) Exogenous gangliosides enhance the interaction of fibronectin with ganglioside-deficien cells. Exp Cell Res 143: 295-302.

37. Ulrich-Bott B, Wiegandt H (1984) Micellar properties of glycosphingolipids in aqueous media. J Lipid Res 25: 1233-1245.

38. Wang J, Mongayt D, Torchilin VP (2005) Polymeric micelles for delivery of poorly soluble drugs: preparation and anticancer activity in vitro of paclitaxe incorporated into mixed micelles based on poly(ethylene glycol)-lipid conjugate and positively charged lipids. J Drug Target 13: 73-80.

39. Danhier F, Magotteaux N, Ucakar B, Lecouturier N, Brewster M, et al. (2009) Novel self-assembling PEG-p-(CL-Co-TMC) polymeric micelles as safe and effective delivery system for paclitaxel. Eur J Pharm Biopharm 73: 230-238.

40. Liebmann JE, Cook JA, Lipschultz C, Teague D, Fisher J, et al (1993) Cytotoxic studies of paclitaxel (Taxol) in human tumour cell lines. Br J Cancer 68: 1104 1109

41. Leonhard V, Beltramo DM, Alasino RV, Bianco ID (2011) Water-soluble pharmaceutical composition comprising at least one therapeutically active substance having hydrophobic properties and at least one compound selected from among sialoglycosphingolipids, glycosphingolipids or a mixture of sialoglycosphingolipids and glycosphingolipids. 